\title{
Massive Phenotypic Measurements Reveal Complex Physiological Consequences of DifFERENTIAL TRANSLATION EFFICACIES
}

\author{
Adam Paul Arkin ${ }^{1,2, *}$ \& Guillaume Cambray ${ }^{3,4, *}$ \\ ${ }^{I}$ Department of Bioengineering, University of California, Berkeley, CA, 94720, USA. ${ }^{2}$ \\ Physical Biosciences Division, Lawrence Berkeley National Laboratory, Berkeley, CA, \\ 94720, USA. ${ }^{3}$ California Institute for Quantitative Biosciences, University of California, \\ Berkeley, CA, 94720, USA. ${ }^{4}$ DGIMI, INRA, Univ. Montpellier, Montpellier, France.
}

* To whom correspondence should be addressed

\begin{abstract}
Control of protein biosynthesis is at the heart of resource allocation and cell adaptation to fluctuating environments. One gene's translation often occurs at the expense of another's, resulting in global energetic and fitness trade-offs during differential expression of various functions. Patterns of ribosome utilization - as controlled by initiation, elongation and release rates - are central to this balance. To disentangle their respective determinants and physiological impacts, we complemented measurements of protein production with highly parallelized quantifications of transcripts' abundance and decay, ribosome loading and cellular growth rate for 244,000 precisely designed sequence variants of an otherwise standard reporter. We find highly constrained, non-monotonic relationships between measured phenotypes. We show that fitness defects derive either from protein overproduction, with efficient translation initiation and heavy ribosome flows; or from unproductive ribosome sequestration by highly structured, slowly initiated and overly stabilized transcripts. These observations demonstrate physiological impacts of key sequence features in natural and designed transcripts.
\end{abstract}

\section{INTRODUCTION}

Timely production of functional proteins to express the most adequate phenotype in a given environment and at minimal biosynthetic cost drives the perpetuation of organisms and their underlying genetic information over time. Control of gene expression consists of two successive processes, transcription and translation, which are often naively treated as independent: transcriptional regulatory networks define the spatio-temporal coexpression of hard-coded DNA information into labile messenger RNAs molecules in a first step; while these informational intermediates enable controllable signal amplification as they are translated into proteins in a second step.

Much attention has been devoted to transcription control as a prime determinant of regulatory network dynamics. The significance of translation control of global regulation has only begun to emerge (Vogel and Marcotte, 2012). Translational processes play a decisive role in the cellular economy, with half the energetic expenditure of growing E. coli cells dedicated to protein biosynthesis and ca. $40 \%$ of that production devoted to making the translation machinery itself (Li et al., 2014). Consequently, cells have evolved remarkably simple and robust regulatory strategies to balance the production of ribosomes and other necessary proteins in response to varying growth conditions (Scott et al., 2014). These differential allocation patterns deeply constrain the proteome and the physiological state of the cell.

There have been a number of intriguing reports questioning the directionality of the central dogma. For example, a transcript's abundance has been linked to its translation efficiency, through modulation of either transcription (Belogurov and Artsimovitch, 2015) or degradation rate (Hui et al., 2014). Precise characterization of such feedbacks is essential to refine our understanding of regulatory networks and improve functional predictions.

We implemented a library comprised of over 244,000 sequence variants of a fluorescent reporter gene designed to systematically explore combinations of the most prominent coding sequence properties believed to impact translation (Figure 1). This library is organized around 56 replicate series - each implementing a fullfactorial design around tight and distinct foci in sequence space. Although varying only 96 nucleotides (nts) at the beginning of a gene controlled by otherwise constant regulatory signals, this design of experiment could at best account for a third of the resulting variance in protein production (companion paper). 
Figure 1 - Molecular design of experiment at the genome scale

(A) High-throughput Design of Experiments at the molecular level. Sequences were designed to produce fullfactorial libraries of 8 sequence properties correlating with protein production in $\mathrm{E}$. coli. Designer sequences were synthesized and cloned in bulk. Various phenotypes are characterized in parallel using high-throughput sequencing as a generic quantitative readout. (B) A standard reporter for translational output. Synthetic sequences are cloned as N-terminal fusions to a modified sfGFP, which produces an invariant reporter upon post-translational processing by the TEV protease. Translation of the reporter is driven by a perfect Shine-Dalgarno motif (SDR, italics) embedded into a novel inducible translational coupling device. Secondary structures in the initiation region can be controllably disrupted by adjusting the influx of leader-bound ribosomes through tunable induction of an unnatural suppressor system. (C) Topology of the sequence properties varied in the factorial design.

To better understand the mechanisms underlying the variable observations, we complemented data on protein production with highly parallel measurements of cellular growth rate, reporter transcript abundance, decay and ribosome loading for virtually all strains in the library. The unique dataset resulting from these experiments permits unraveling of the mechanistic consequences of sequences variations on a core cellular process and their significance in impacting cellular fitness.

In this paper, we detail our design framework and dissect the impact of the designer sequence perturbations on protein production in different conditions of translational coupling. A more systemic analysis integrating these results with the other phenotypic responses is presented in a companion paper.

\section{RESULTS}

Coding sequence perturbations reveal a biphasic relationship between protein production and cell growth

Gratuitous expression of heterologous genes imposes a global cost on the cell, which can result in severe growth defects. This burden reflects accrued consumption of nucleotides, amino acids and other metabolites, as well as the temporary mobilization of limited cell resources, such as tRNA and ribosomes (Ceroni et al., 2015; Scott et al., 2010; Stoebel et al., 2008). In theory, these complex physiological perturbations are strongly dependent on the interplay between translation initiation and elongation rates (Shah et al., 2013). Since the sequence variations engineered in our library affect both rates (companion paper), we suspected substantial physiological differences between strains. We used high-throughput sequencing of the designed sequences to derive parallel measurements of relative growth rates from bulk competition experiments within the entire library (Hietpas et al., 2011; van Opijnen et al., 2009).

We first propagated the library by serial dilution in the same rich, controlled medium as previously used for measuring protein production. For each strain, we estimated relative growth rate using the log-ratios of sequencing read frequencies measured in the propagated populations to those observed in the initial population. To ensure we had both the adequate read depth across the entire library while still obtaining a good dynamic range for growth rate estimation, we combined measurements of competitions after $c a$. 13, 28 and 60 generations (Material and methods; Figure S2ABCD). Based on three replicate competition assays at generation 60 , we estimated a reasonably low experimental error for this type of batch competition assay (5\% of the total variance). We were thus able to derive precise measurements of growth rate in regular conditions $\left(\mathrm{W}_{\mathrm{NC}}\right)$ for 233,846 strains.

As observed for protein production, the distribution of growth rates varies greatly between factorial series (Figure 2A). The sequence properties implemented in our molecular Design of Experiments (Figure 1C) and their second-order interactions account for only 5-31\% of the variance in $\mathrm{W}_{\mathrm{NC}}$, as quantified by ANOVA within each factorial series (14\% on average; Figure $2 \mathrm{~B})$. The secondary structure across the start codon $\left(\mathrm{STR}_{-30:+30}\right)$ and that designed farther in the coding sequence $\left(\mathrm{STR}_{+31:+90}\right)$ show the most prevalent effects, accounting for $30 \%$ and $19 \%$ of explained variance on average, respectively. These structures have contrasting effects and sizeable interactions: weak $\mathrm{STR}_{-30:+30}$ negatively impact growth whereas weak $\mathrm{STR}_{+31:+90}$ has a positive effect, especially when associated with strong STR $_{-30:+30}$ and weak $\mathrm{STR}_{+01:+60}$ (Figure S2E).

Perhaps explaining the modest performance of this linear model, our data show a strongly non-monotonic relationship between $\mathrm{W}_{\mathrm{NC}}$ and protein production $\left(\mathrm{P}_{\mathrm{NC}}\right.$, Figure 2C). The expected anti-correlation is confined to higher production, whereas lower producers demonstrate 
bioRxiv preprint doi: https://doi.org/10.1101/209098; this version posted October 25, 2017. The copyright holder for this preprint (which was not certified by peer review) is the author/funder, who has granted bioRxiv a license to display the preprint in perpetuity. It is made available under aCC-BY-NC-ND 4.0 International license.

unexpected spread toward low growth. This relationship is generally well captured by quadratic regressions of $\mathrm{P}_{\mathrm{NC}}$ on $\mathrm{W}_{\mathrm{NC}}(1-52 \%$ of the total variance across series; $28 \%$ on average, with $19 \%$ by the squared component only; Figure 2D).

These regressions expose direct contributions to growth that are not mediated by effects on protein production. On average, design properties and their interactions explain $10 \%$ of the variance in $\mathrm{W}_{\mathrm{NC}}$ not accounted by $\mathrm{P}_{\mathrm{NC}}$ (Figure 2D). The contribution of STR $30:+30$ to $\mathrm{W}_{\mathrm{NC}}$ is then reduced to only $11 \%$ of the explained residual variance (Figure 2E). The apparent effect of this structure on $\mathrm{W}_{\mathrm{NC}}$ is therefore largely due to

A 1.2
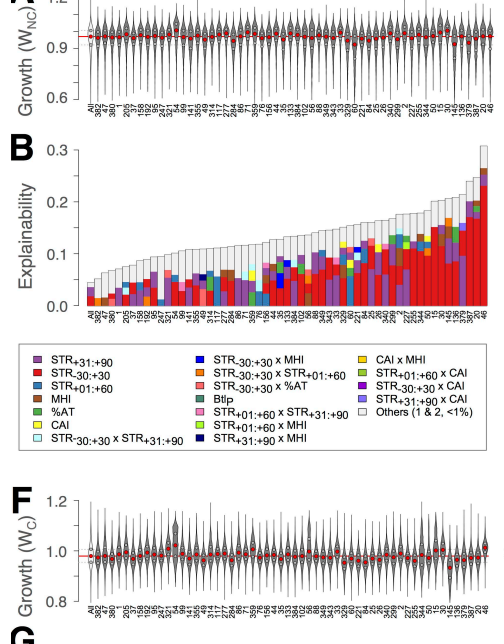

G

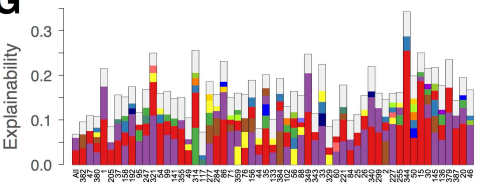

K

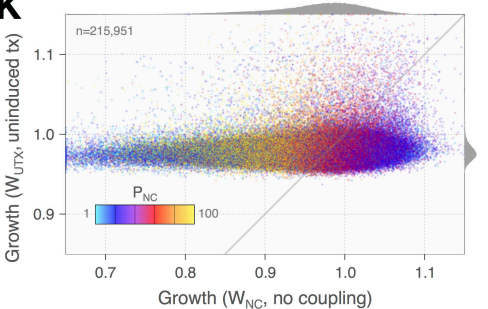

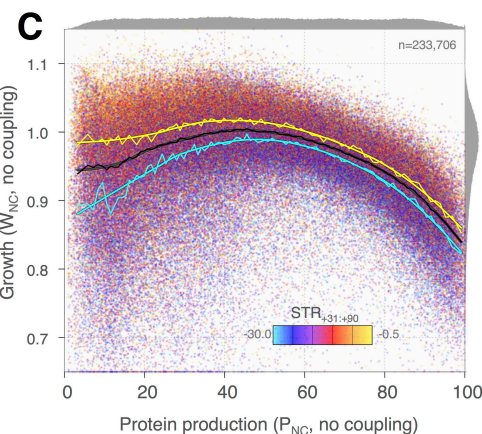

Protein production ( $P_{N C}$, no coupling)
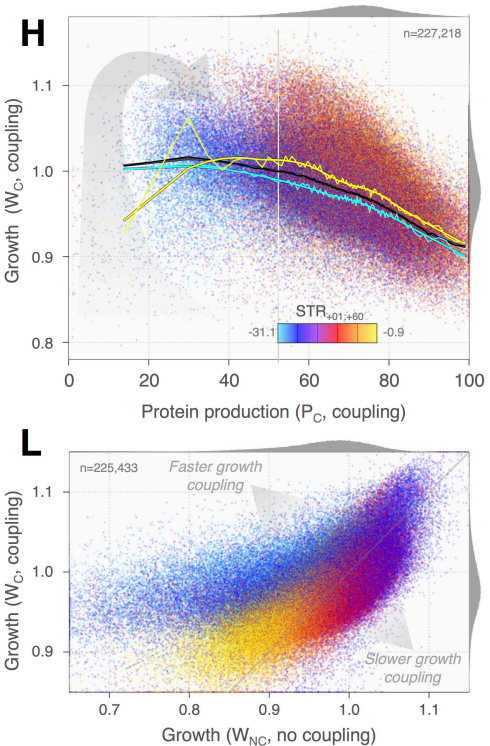
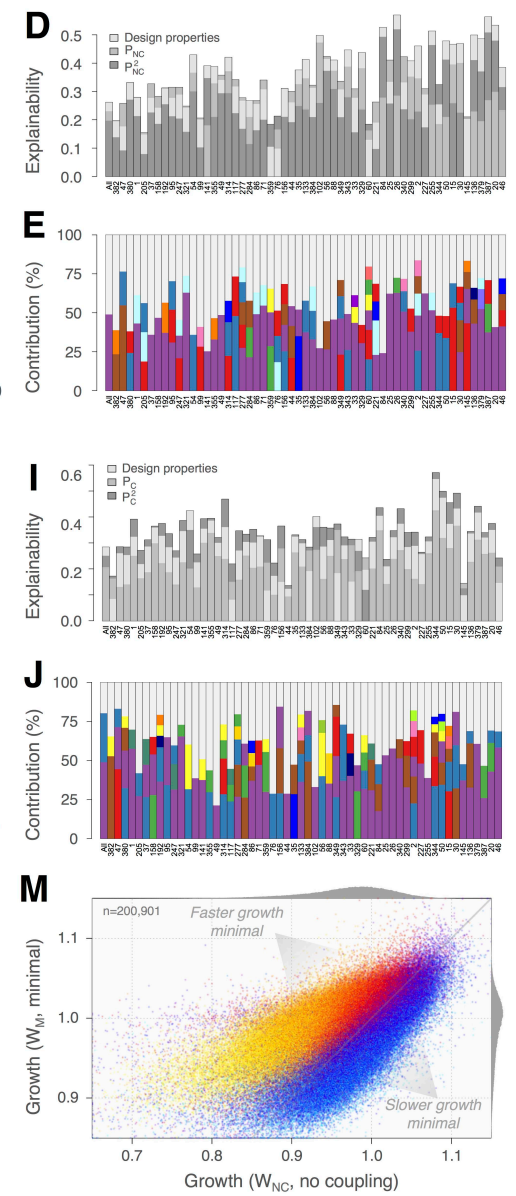

Figure 2 - Unexpected growth defects associated with low translation initiation

(AB) Highly variable growth profiles and corresponding patterns of explanation between replicate factorial series. Violin plots in (A) show the distribution of growth rate under non-coupling condition $\left(\mathrm{W}_{\mathrm{NC}}\right)$ for each series. Red and grey dots mark medians and interquartile ranges, respectively. Stacked bars in (B) show corresponding variance decomposition by ANOVAs based on the sequence design properties. Effects $\geq 1 \%$ are sorted in decreasing order from bottom to top and colored as shown. Other effects are grouped on top in grey. (CDE) Unexpected relationships between growth, protein production and within-genes mRNA structures. Scatter plot of $\mathrm{W}_{\mathrm{NC}}$ versus $\mathrm{P}_{\mathrm{NC}}$ colored by $\mathrm{STR}_{+31:+90}$, as shown $(\mathbf{C})$. The dark lines mark the median $\mathrm{W}_{\mathrm{NC}}$ for each percentile of $\mathrm{P}_{\mathrm{NC}}($ thin line) and show a loess smoother highlighting the trend (thick line). Low $\mathrm{P}_{\mathrm{NC}}$ is associated with $\mathrm{W}_{\mathrm{C}}$, resulting in a strongly biphasic relationship. Yellow and cyan lines show the top and bottom deciles of $\mathrm{STR}_{+31:+90}$, respectively. $\mathrm{STR}_{+31:+90}$ is positively correlated with $\mathrm{W}_{\mathrm{NC}}$, especially at low $\mathrm{P}_{\mathrm{NC}}$. A multiple linear regression of $\mathrm{W}_{\mathrm{NC}}$ including $\mathrm{P}_{\mathrm{NC}}$ and $\mathrm{P}_{\mathrm{NC}}{ }^{2}$ as explanatory variables improves explanatory patterns (D). The importance of the squared component underscores non-linearity in most series. Bars in (E) detail the relative contributions of design properties in this regression and confirm the prominent impact of STR $+31:+90$ on $\mathrm{W}_{\mathrm{NC}}$ across series. (FGHIJ) Same analyses under translational coupling. Epigenetic improvement of initiation causes substantial linearization of the relationship between $\mathrm{P}_{\mathrm{C}}$ and $\mathrm{W}_{\mathrm{C}}$ (HI). The impact of $\mathrm{STR}_{+31:+90}$ is largely maintained (J). (KLM) Low rates of translation initiation are linked to slow growth. Scatter plots of growth rates in different culture conditions against the reference $\mathrm{W}_{\mathrm{NC}}$, colored by $\mathrm{P}_{\mathrm{NC}}$ as shown. Expression of reporter transcripts is necessary to observe growth differences (K). Improving initiation by translational coupling increases growth rates amongst lowest protein producers $(\mathbf{L})$. Lower ribosome availability upon growth in minimal media increases the growth defect in low protein producers $\mathbf{( M )}$. 


\section{Manipulation of expression uncover distinct costs associated to translation}

We performed additional competitions in different growth conditions to clarify how these associations relate to the expression of the reporter (Material and methods). We first propagated three control populations for ca. 60 generations without inducing transcription of the reporter. As expected, the growth rates observed in this condition $\left(\mathrm{W}_{\mathrm{UTX}}\right)$ are much less variable and represent only $5 \%$ of the variance quantified above (Figure $2 \mathrm{~K}$ ). These results establish the necessity of transcription to the selection pattern observed previously.

Our reporter system is equipped with an inducible translation-coupling device capable of mitigating the adverse effect of mRNA secondary structure on initiation (companion paper and Figure 1B). To determine the effect of increasing initiation rates, we conducted competition experiments for populations propagated for ca. 26 and 33 generations under coupling and could derive $\mathrm{W}_{\mathrm{C}}$ for 229,224 strains.

Improving initiation rates through elimination of mRNA structure around the Shine-Dalgarno motif decreases the variance in growth rate by about two thirds, while generally maintaining the relative growth profiles differences between individual series (Figure 2AF). ANOVAs on $\mathrm{W}_{\mathrm{C}}$ globally provide a comparable picture to that obtained for $\mathrm{W}_{\mathrm{NC}}$, with dominant effects of STR $_{-30:+30}$ and STR $_{+31:+90}(28 \%$ and $26 \%$ of the explained variance on average, respectively; Figure $2 \mathrm{G}$ ). $\mathrm{W}_{\mathrm{C}}$ and protein production $\left(\mathrm{P}_{\mathrm{C}}\right)$ display a drastically more linear relationship under coupling, demonstrating that the phenomenon of low initiation is in itself a key determinant of the fitness defects observed at low $\mathrm{P}_{\mathrm{NC}}$ (Figure 2HL). Only 0-15\% variance in $\mathrm{W}_{\mathrm{C}}$ is accounted for by the squared component in quadratic regressions involving $\mathrm{P}_{\mathrm{C}}$ (Figure 2I). Design properties then explain $3-24 \%$ of the residual variance, again with a large dominance of STR $+31:+90$ and $\mathrm{STR}_{+01:+60}(28$ and $14 \%$ of explained variance on average, respectively; Figure 2J). Consistently, the few strains that are refractory to coupling due to overly strong $\mathrm{STR}_{+01:+60}$ (companion paper) remain associated with an inflexion toward lower growth (Figure 2H). Hence, low initiation rates as determined by structures in the translation initiation region (TIR) are necessary to the mechanism causing unexpected growth defects at low protein production.

To further probe the link between growth and translational regime, we sought to reduce the translation capacity of the cells. Bacteria grown in media with less nutrients are known to grow slower and produce fewer ribosomes (Schaechter et al., 1958). We thus propagated our library in minimal media for ca. 33 generations and could derive $\mathrm{W}_{\mathrm{M}}$ for 201,893 strains. Low protein producing strains systematically exhibit lower WM for a given $\mathrm{W}_{\mathrm{NC}}$ (partial correlation $\rho=0.68$, Figure $2 \mathrm{M}$ ). The initiation-limiting properties of strong STR $_{-30:+30}$ are no longer associated with a positive impact on growth (Figure S2F). The pattern of interaction with other structures is nonetheless maintained, such that strong $\mathrm{STR}_{-30:+30}$ combined with strong $\mathrm{STR}_{+31:+90}$ but weak
STR $+01:+60$ determine lowest $\mathrm{W}_{\mathrm{M}}$ (Figure S2F). These observations expose a component of the cost associated with translation that: i) is mechanistically distinct from the actual level of protein production; ii) is dependent on strong transcript folding; and iii) is amplified when fewer ribosomes are available.

\section{Differences in mRNA abundance are largely shaped by differential decay}

In our system, transcription is driven by a constant promoter whose start site is located $c a$. 100 nts upstream of the designed sequences. Although we cannot rule out occasional interactions between designed sequences and transcription machinery, we do not expect extensive variations in transcription rates across strains (Kosuri et al., 2013; Mutalik et al., 2013). Instead, systematic differences in steady-state mRNA levels could arise from differential degradation kinetics arising from the sequence variations. Multiple lines of evidence indicate that translation rate and transcript degradation are intricately linked (Deana and Belasco, 2005; Huch and Nissan, 2014). Accordingly, coding sequence properties such as codon usage bias and mRNA folding have been associated with mRNA decay (Boël et al., 2016; Hui et al., 2014; Lenz et al., 2011; Presnyak et al., 2015).

We developed a targeted sequencing assay to follow the relative abundances of reporter transcripts after transcription was arrested in vivo (Figure 3A). Using this procedure, we could estimate steady-state RNA abundance $\left(\mathrm{RNA}_{\mathrm{SS}}\right)$, RNA half-lives $\left(\mathrm{RNA}_{\mathrm{HL}}\right)$ and an

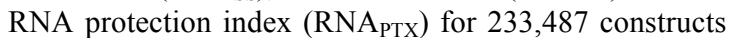
(Material and Methods and Figure S3ABC).

This experiment revealed substantial variability in $\mathrm{RNA}_{\mathrm{SS}}$ over the whole library $(\mathrm{CoV}=0.44)$, as well as marked differences between factorial series (Figure $3 \mathrm{~B}$ ). Estimates of $\mathrm{RNA}_{\mathrm{HL}}$ are equally variable though less reproducible $(\mathrm{CoV}=0.41$, Figure $3 \mathrm{C}$ and $\mathrm{S} 3 \mathrm{C})$, with a median half-life of 4.8 min typical of E. coli. Although longer-lived transcripts should be more abundant, the association between $\mathrm{RNA}_{\mathrm{HL}}$ and $\mathrm{RNA}_{\mathrm{SS}}$ is overall very poor ( $\mathrm{r}=0.06$, Figure S3D). Closer examination reveals that decay profiles are strongly dependent on protein production (Figure $3 \mathrm{C}$ ). We identified a non-monotonic relationship between $\mathrm{RNA}_{\mathrm{HL}}$ and $\mathrm{P}_{\mathrm{NC}}$, such that transcripts with highest apparent stabilities are partitioned to the tails of the protein distribution (Figure 3D). In this context, the correlation between $\mathrm{RNA}_{\mathrm{HL}}$ and RNA $_{\mathrm{SS}}$ decreases smoothly with $\mathrm{P}_{\mathrm{NC}}$ from $c a$. 0.4 to $c a$. 0.3 , restricting the expected positive association to the lower third of protein producers (Figure $3 \mathrm{~F}$ and $\mathrm{S} 3 \mathrm{D}$ ). These results suggest that distinct mechanisms are determining decay rates under extreme translational regimes.

The fraction of $\mathrm{RNA}_{\mathrm{SS}}$ asymptotically left after decay (RNA PTX $_{\text {) }}$ is also strongly correlated with $\mathrm{P}_{\mathrm{NC}}$ $(\mathrm{r}=0.76$, Figure 3E). We initially introduced this parameter because it afforded better decay fits, but its biological significance was unclear. Our observation implies that individual transcripts are protected from 
bioRxiv preprint doi: https://doi.org/10.1101/209098; this version posted October 25, 2017. The copyright holder for this preprint (which was not certified by peer review) is the author/funder, who has granted bioRxiv a license to display the preprint in perpetuity. It is made available under aCC-BY-NC-ND 4.0 International license.

complete degradation to an extent that depends on their effective translation rate (Figure $3 \mathrm{C}$, inset). We have shown that the competition between ribosome binding and TIR folding is the chief determinant of initiation rates (companion paper). After transcription is stopped, the quantity of labile mRNAs decreases quickly, while that of stable t- and rRNA should remain approximately constant on the timescale of the assay. Thus, the relative titer of free ribosomes increases during the decay assay, promoting gradually improved initiation of the remaining transcripts (Bulmer, 1991; Shah et al., 2013). In this dynamic process, weaker structures are outcompeted faster $\left(r=0.37\right.$ between RNA ${ }_{\text {PTX }}$ and STR. $30:+30$ structure), resulting in larger protection amongst high protein producers.

Strains showing higher $\mathrm{RNA}_{\mathrm{SS}}$ undergo slower and eventually lower protection ( $\mathrm{r}=-0.39$, Figure $3 \mathrm{C}$ and $3 \mathrm{E})$.
Distributing a finite quantity of ribosomes over more transcripts leads to lower translation of individual transcripts (see Figure 5D), hence to less protection for longer times during the decay assay. Thereby, the apparent half-lives estimated for high protein producers capture the swiftness of the protection process during the assay rather than the stability of the transcripts per sehence the negative correlation between RNA $_{S S}$ and $\mathrm{RNA}_{\mathrm{HL}}$ at high translation regime (Figure $3 \mathrm{DF}$ and S3D).

\section{Dual dependence of $R N A$ decay on translation regime and secondary structures}

Transcript abundances are seemingly shaped by the antagonistic actions of two distinct translation-dependent mechanisms on decay, whose complex interplay
A

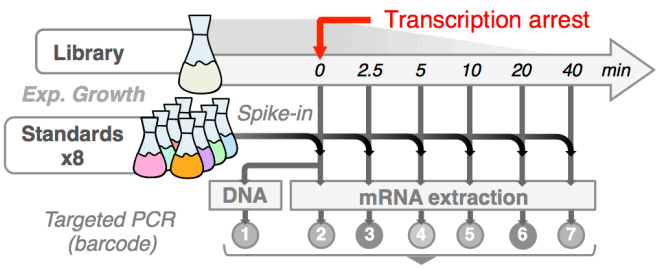

HT Sequencing $<$ Equimolar mix
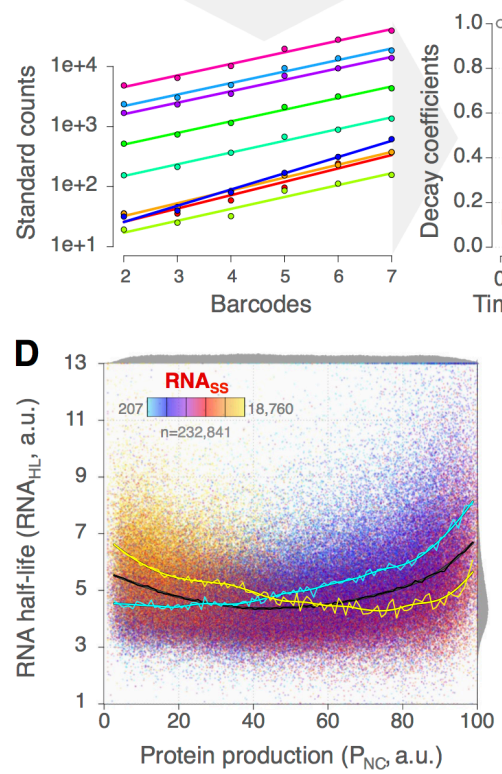
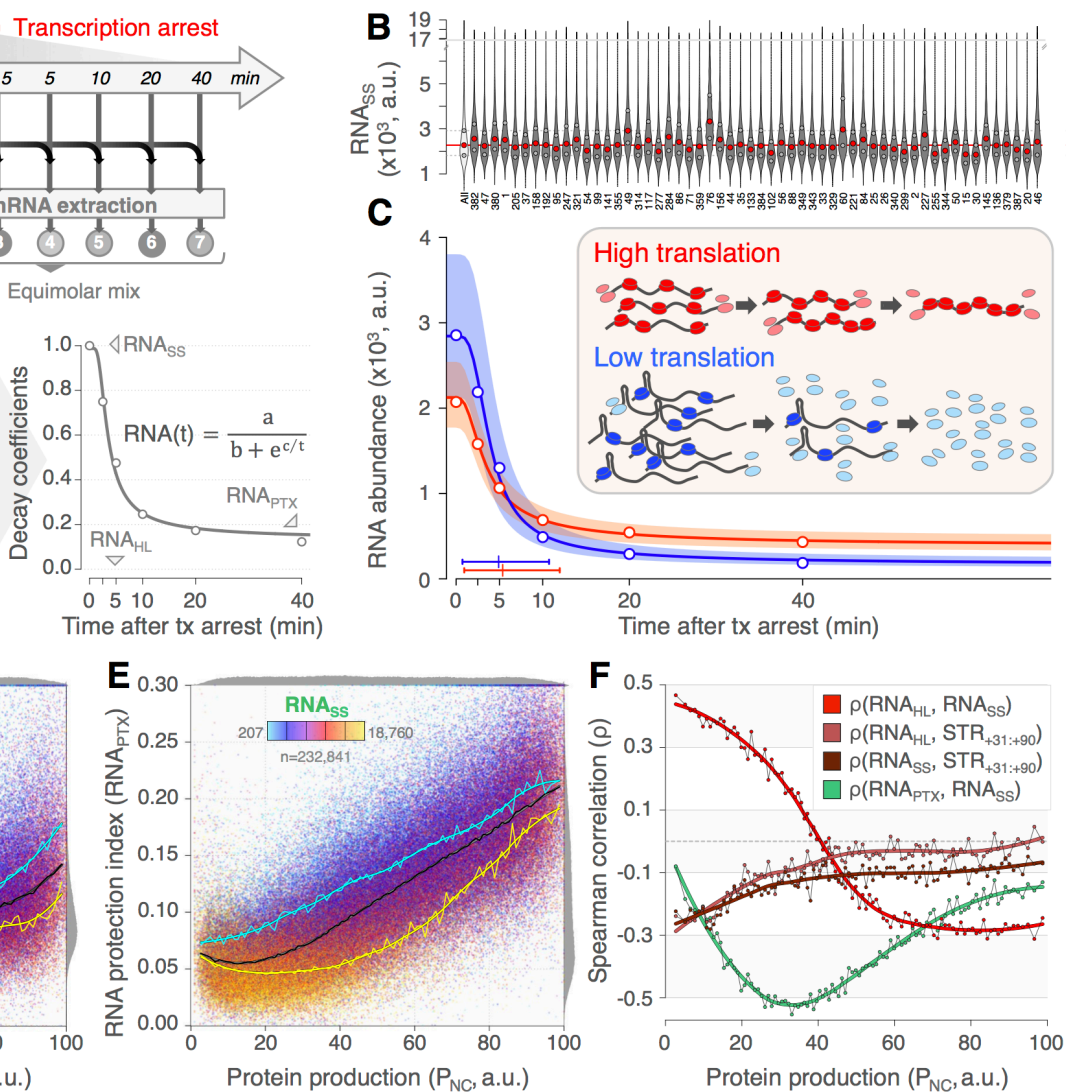

Figure 3 - Translation rates affect RNA abundance

(A) High-throughput assay of RNA decay. Constant quantities of standard strains are spiked-in library samples. Standard sequencing reads increase as reporter transcript decay, which defines corrective coefficients. Corrected time series for each strain are fit to an exponential decay model to estimate RNA abundance at steady state $\left(\mathrm{RNA}_{\mathrm{SS}} ; \mathrm{t}=0\right)$, transcript half-life $(\mathrm{RNA} \mathrm{HL})$ and the final fraction

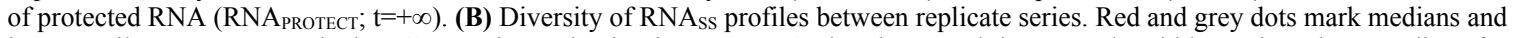
interquartile ranges, respectively. (C) Protein production impacts RNA abundance and decay. Red and blue points show medians for the top and bottom deciles of $\mathrm{P}_{\mathrm{NC}}$, respectively. Red and blue lines and shadings mark corresponding decay fits and interquartile rang-

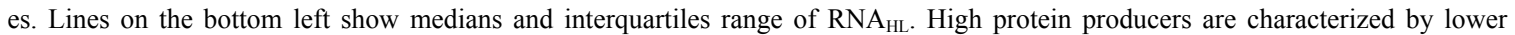

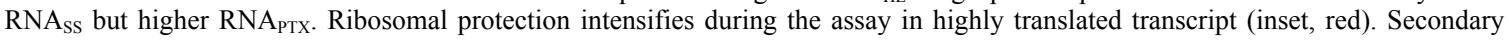
structures limit ribosomal protection but increase transcripts stability and RNA SS (inset, blue). (DEF) Decay assay artifacts expose complex interactions between degradation and translation. Scatter plot of RNA $\mathrm{HL}_{\mathrm{HL}}$ (D) and RNA $\mathrm{DPX}_{\mathrm{PT}}$ (E) versus $\mathrm{P}_{\mathrm{NC}}$, colored by RNA as shown. Dark lines mark median $\mathrm{RNA}_{\mathrm{HL}}$ or RNA $\mathrm{P}_{\mathrm{PT}}$ for each percentile of $\mathrm{P}_{\mathrm{NC}}$ and the corresponding loess smoothers. Yellow and cyan lines show the top and bottom deciles of RNA $\mathrm{R}_{\mathrm{SS}}$, respectively. (F) Various correlations for each percentile of $\mathrm{P}_{\mathrm{NC}}$, as shown. Positive association between $\mathrm{RNA}_{\mathrm{HL}}$ and RNA $\mathrm{SS}$ is restricted to low $\mathrm{P}_{\mathrm{NC}}$ and progressively inverted, reflecting swifter protection of fast initiated transcript (see panel $\mathrm{C}$, red inset). RNA $\mathrm{P}_{\mathrm{PT}}$ is linearly related to $\mathrm{P}_{\mathrm{NC}}$ and modulated by RNA $\mathrm{AS}_{\mathrm{SS}}$ Stronger structures are associated with increased $\mathrm{RNA}_{\mathrm{HL}}$ and $\mathrm{RNA}_{\mathrm{SS}}$, especially at low $\mathrm{P}_{\mathrm{NC}}$. 
bioRxiv preprint doi: https://doi.org/10.1101/209098; this version posted October 25, 2017. The copyright holder for this preprint (which was not certified by peer review) is the author/funder, who has granted bioRxiv a license to display the preprint in perpetuity. It is made available under aCC-BY-NC-ND 4.0 International license.

Figure 4 - Slow growth caused by pathological cumu-lation of stable transcripts at low translation regime

(ABC) Scatter plots of two measured phenotypes, colored by a third as shown. Lines show loess regressions for every decile of the latter quantity, following the same color code. Line widths provide perspective corresponding to viewpoints in $\mathbf{D}$. The biphasic relationship between $\mathrm{W}_{\mathrm{NC}}$ and $\mathrm{P}_{\mathrm{NC}}$ in $\mathbf{A}$ mirrors that between $\mathrm{RNA}_{\mathrm{SS}}$ and $\mathrm{P}_{\mathrm{NC}}$ in $\mathbf{C}$. It stems from the strong negative correlation between $\mathrm{W}_{\mathrm{NC}}$ and RNA $_{\text {ss, }}$, which decreases with $\mathrm{P}_{\mathrm{NC}}$ (B and see inset in panel A for every percentile of $\mathrm{P}_{\mathrm{NC}}$ ). (D) Three-dimensional phenotypic envelope of the library. Colored layers mark increasing data densities. Top-right arrows show viewpoints for panels ABC.
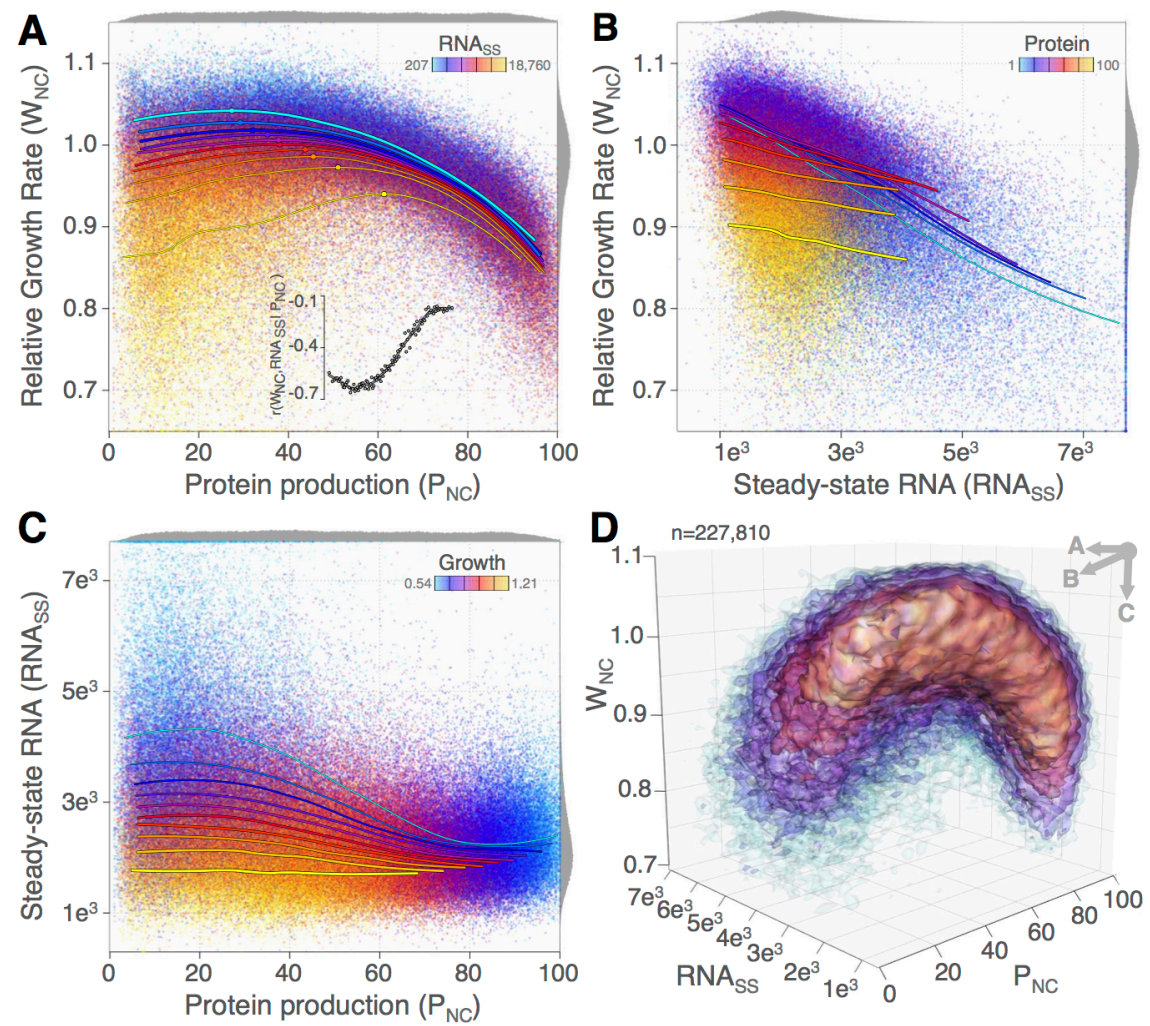

eventually determines a biphasic relationship between $\mathrm{P}_{\mathrm{NC}}$ and $\mathrm{RNA}_{\mathrm{SS}}$ (Figure 4C).

At low initiation, transcript stability is largely determined by secondary structures that can hinder endonucleolytic cleavages by RNase E (McDowall et al., 1995) and processive degradation by 3 ' exoribonucleases (Hui et al., 2014). Because both $\mathrm{STR}_{-30:+30}$ and $\mathrm{STR}_{+01:+60}$ are primary determinants of initiation rates (companion paper), their impacts on stability are confounded and challenging to discriminate. The effect of $\mathrm{STR}_{+31:+90}$ is more apparent, especially in the low translation regime (Figure 3F and S3EF).

Ribosomes are intrinsically capable of unfolding transcripts during initiation (Duval et al., 2013) and subsequent elongation ( $\mathrm{Qu}$ et al., 2011), with rates commensurate to the thermodynamic stabilities of the structures. These processes likely promote degradation through transient exposure of single-stranded RNA substrates to ribonucleases. Accordingly, the dependence of $\mathrm{RNA}_{\mathrm{HL}}$ and $\mathrm{RNA}_{\mathrm{SS}}$ on secondary structures diminishes with increasing $\mathrm{P}_{\mathrm{NC}}$ (Figure $3 \mathrm{~F}$ ), resulting in lower $\mathrm{RNA}_{\mathrm{SS}}$ at intermediate translation regimes (Figure 4C).

At higher translation rates, heavy ribosome flows can compete kinetically with ribonucleolytic attacks (Boël et al., 2016) and particularly with the decay-initiating action of RNase E (Braun et al., 1998). Although blatant in the decay data (Figure $3 \mathrm{E}$ ), this ribosome protection only results in a modest increase of $\mathrm{RNA}_{\mathrm{SS}}$ amongst the highest protein producers during exponential growth (Figure 4C). This discrepancy probably reflects the limiting nature of ribosomes in growing cells, which is progressively relieved during the decay assay (Figure $3 \mathrm{C}$, inset). The negative correlation between $\mathrm{RNA}_{\mathrm{SS}}$ and RNA $_{\text {PTX }}$ strongly supports this view (Figure $3 E F$ ).

The dual impact of folding on stability and translation gives rise to intricate functional interactions between designed structures (Figure S3G). For example, the stabilizing effect of strong $\mathrm{STR}_{+31:+90}$ is particularly marked when combined with strong STR $_{-30:+30}$ (which effects low initiation) and weak $\mathrm{STR}_{+01:+60}$ (which minimizes thermodynamic competition with the two other structure). Similarly, the association between strong $\mathrm{STR}_{+01:+60}$ and lower transcript protection is more profound when initiation is not otherwise limited by potent $\mathrm{STR}_{-30:+30}$ and its folding not competed by strong $\mathrm{STR}_{+31:+90}$.

\section{Variations in RNA abundance impact cell growth}

Variations in $\mathrm{RNA}_{\mathrm{SS}}$ are strongly anti-correlated with $\mathrm{W}_{\mathrm{NC}}(\mathrm{r}=-0.45$, Figure $4 \mathrm{AB})$. Reflecting the dependence of RNA $\mathrm{RS}_{\mathrm{SS}}$ on translation (Figure $4 \mathrm{C}$ ), the strength of this association declines smoothly with $\mathrm{P}_{\mathrm{NC}}$ (Figure 4A, inset). The co-distribution of these three phenotypic measures outlines a well-defined envelope that captures their constrained interdependences (Figure 4D and S4). The highest $\mathrm{RNA}_{\mathrm{SS}}$ are found amongst the lowest $\mathrm{P}_{\mathrm{NC}}$ and appear to determine the unexpectedly low $\mathrm{W}_{\mathrm{NC}}$ observed in those strains. The variability in $\mathrm{RNA}_{\mathrm{SS}}$ narrows down with increasing $\mathrm{P}_{\mathrm{NC}}$ and its apparent contribution to growth defects decreases. Instead, $\mathrm{W}_{\mathrm{NC}}$ becomes increasingly dominated by the cost of protein 
production. The cost associated with RNA be amplified at lower $\mathrm{P}_{\mathrm{NC}}$, as initially noted for the causative STR $_{+31:+90}$ (Figure 2C).

The transition from low to medium $\mathrm{P}_{\mathrm{NC}}$ is generally accompanied by an increase in $\mathrm{W}_{\mathrm{NC}}$, despite the added cost of accrued protein biosynthesis. Sequence variants with very low translation rates exhibit strong $\mathrm{STR}_{-30:+30}$ and/or $\mathrm{STR}_{+01:+60}$ in vivo. Since these features are also associated with increased transcript stabilities in these absence of translating ribosomes, the occurrence of sequence determining low $\mathrm{RNA}_{\mathrm{SS}}$ is inherently sparser amongst lower than more intermediate protein producers. Given the apparent cost of $\mathrm{RNA}_{\mathrm{SS}}$, this mechanistic contingency reduces the median growth rate observed at low protein production regimes. Nevertheless, fitness optima still lie at intermediate translation regimes when variations in $\mathrm{RNA}_{\mathrm{SS}}$ are controlled for (see Figure 4A, points on regression lines). The coordinates of these optima are tightly linked to $\mathrm{RNA}_{\mathrm{SS}}$, with higher $\mathrm{RNA}_{\mathrm{SS}}$ associated with lower optimal $\mathrm{W}_{\mathrm{NC}}$ at higher $\mathrm{P}_{\mathrm{NC}}$.

\section{Initiation-based ribosome sequestration help disentangling cellular labor from material costs}

The observations above suggest the existence of a negative interaction between the physiological cost of high mRNA abundance and that of slow initiation. Since the sequestration of nucleotides and phosphate in polymerized transcripts is benign to $E$. coli cells grown in rich medium (Stoebel et al., 2008), high RNA $\mathrm{SS}_{\mathrm{SS}}$ is unlikely to be the proximal cause of the observed costs. However, high heterologous transcript abundance can have dramatic consequences on the allocation of limited ribosomal resources toward the host transcriptome (Shah et al., 2013), eventually leading to decreased growth rates (Scott et al., 2010). Such differential ribosome mobilization by variant library transcripts provides an attractive mechanistic basis for the observed associations.

To examine this, we performed a deep-sequencingbased polysome profiling to quantify the distribution of ribosomes densities associated with each transcript variant (Figure 5A). We derived the relative enrichment of individual constructs in each of the first five polysome fractions and obtained a polysome profile for 240,403 strains (Material and Methods).

Although the shape of such profiles conveys important information regarding the translation kinetics of a given transcript, it is difficult to analyze at scale. We first conflated the data into a single measure that captures the average number of ribosome per reporter transcript. This mean ribosomal density (MRD) is highly correlated with $\mathrm{P}_{\mathrm{NC}}(\mathrm{r}=0.73)$, so that every ribosome density corresponds to a tight range of protein production (Figure 5B). Two sequence properties-CAI and STR $_{-30:+30}$ - show interesting signals in this context.

For a given density, $\mathrm{P}_{\mathrm{NC}}$ increases with CAI (Figure $5 \mathrm{~B})$. The strength of this association smoothly increases with MRD, as translation becomes less limited by
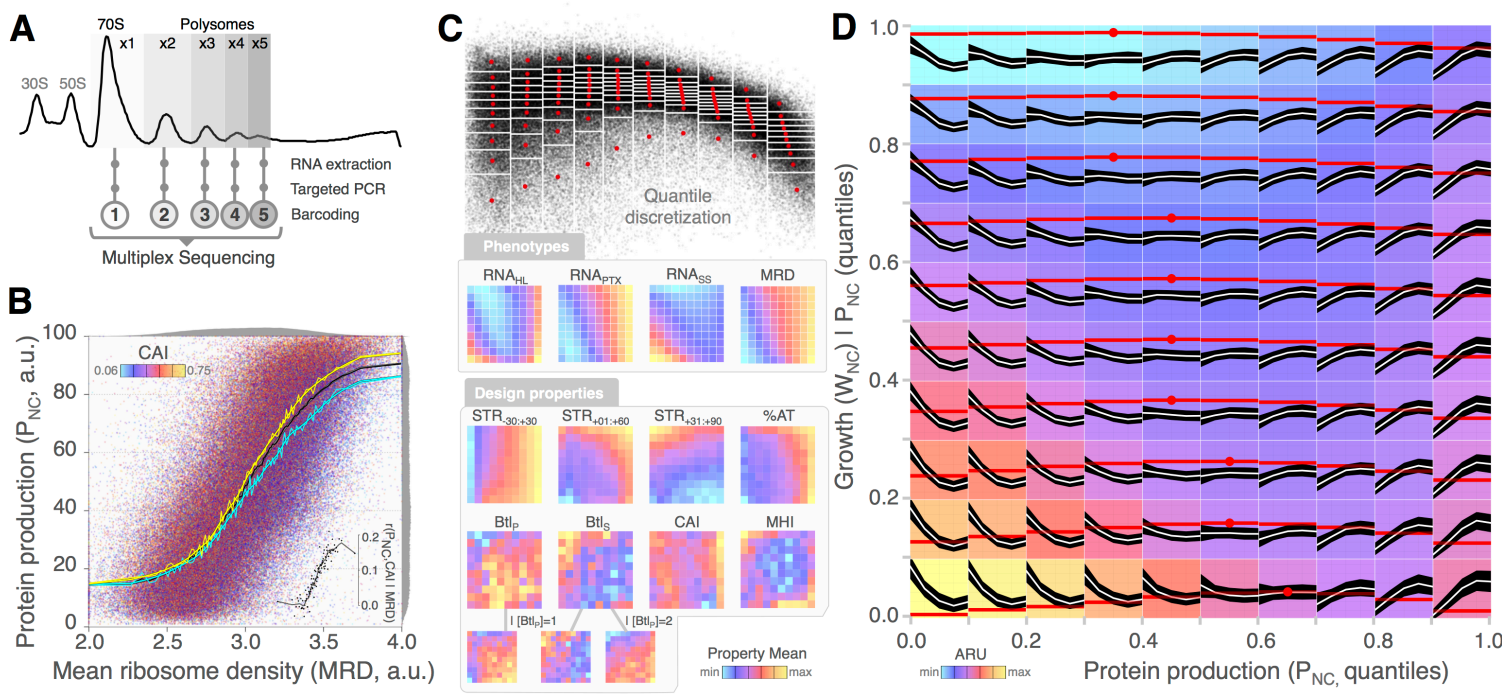

Figure 5 - Ribosomal density profiles identify tipping points of translation cost

(A) High-throughput targeted polysome profiling. The first five polysome fractions were extracted from a sucrose gradient, barcoded and sequenced in multiplex. (B) Codon usage modulates protein production fro a given ribosomal density. Scatter plot of $\mathrm{P}_{\mathrm{NC}}$ versus the mean ribosomal density (MRD), colored by CAI as shown. The dark lines mark the median $\mathrm{P}_{\mathrm{NC}}$ for each density percentile (thin line) and a loess smoother highlighting the trend (thick line). Yellow and cyan lines show the top and bottom deciles of CAI, respectively. The correlation between CAI and $\mathrm{P}_{\mathrm{NC}}$ increases with very percentile of ribosomal density (inset). (C) Coarse-grained grids of $\mathrm{W}_{\mathrm{NC}}$ versus $\mathrm{P}_{\mathrm{NC}}$. Top: Data are binned first by deciles of $\mathrm{P}_{\mathrm{NC}}$ and then by deciles of $\mathrm{W}_{\mathrm{NC}}$. Each bin comprise $\sim 2,250$ strains. Red crosses mark local averages. Bottom: Bins are color-coded to show the range of means in quantity indicated in each vignette. (D) Polysome profiles vary smoothly in this phenotypic space. White lines and dark shadings show median and interquartile ranges of the relative abundances of polysome fractions, from monosome (left) to pentasome (right). Red lines and points mark mean $\mathrm{W}_{\mathrm{NC}}$ and corresponding row-wise optima. Background is color-coded by the apparent ribosome utilization (ARU, MRD times RNA $A_{s S}$ ). Increased prevalence of monosomes is associated with lower $\mathrm{W}_{\mathrm{NC}}$ for a given $\mathrm{P}_{\mathrm{NC}}$ (column, top to bottom). Row-wise $\mathrm{W}_{\mathrm{NC}}$ optima correspond to balanced initiation versus elongation (flat profile). 
initiation (inset). This result is consistent with the expected effect of rarely used codons in slowing down elongation rates as a consequence of low abundance of cognate tRNA species (Bulmer, 1991). Increasing ribosome densities further reveals a strengthening association between CAI and $\mathrm{RNA}_{\mathrm{PTX}}$ (up to $\mathrm{r}=0.17$, Figure S5A) that underpins a similar though weaker correlation with $\mathrm{RNA}_{\mathrm{SS}}$ (up to $\mathrm{r}=0.11$, Figure S5B). These data support the involvement of heavy and smooth ribosome trafficking in transcript protection.

Stronger $\mathrm{STR}_{+31:+90}$ is associated with increased $\mathrm{P}_{\mathrm{NC}}$ for a given MRD, especially at medium densities (up to $\mathrm{r}=-0.22$, Figure $\mathrm{S} 5 \mathrm{C}$ ), while it should instead slow elongation down and determine lower $\mathrm{P}_{\mathrm{NC}}$, as observed for low CAI. To resolve this discrepancy, we consider the converse relationship, whereby strong $\mathrm{STR}_{+31:+90}$ is associated with increasingly lower densities as $\mathrm{P}_{\mathrm{NC}}$ diminishes. This pattern almost perfectly mirrors the association of $\mathrm{STR}_{+31:+90}$ with $\mathrm{RNA}_{\mathrm{SS}}$ (Figure S5D). Now, higher RNA $\mathrm{SS}_{\mathrm{SS}}$ is globally associated with lower loads on individual transcripts $(\mathrm{r}=-0.31)$. It is therefore likely that the apparent effect of $\mathrm{STR}_{+31:+90}$ on MRD is an indirect consequence of the intricate, translationdependent effects of secondary structures on RNA stability and abundance (Figure S5E). These observations illustrate the difficulties in untangling causality amongst many dependencies existing in the data.

To better characterize polysome profiles, we binned the library into equally sized subpopulations covering the extent of the protein-growth phenotypic space (Figure 5C). We then derived a statistical representation of the $\sim 2,270$ profiles in each bin (Figure 5D). At low $\mathrm{P}_{\mathrm{NC}}$, profiles are dominated by low fractions characteristic of low initiation. As $\mathrm{P}_{\mathrm{NC}}$ increases, profiles become increasingly flatter and progressively shift toward larger representation of dense fractions indicative of limiting elongation. Strikingly, the flat profile that marks the equilibrium between initiation and elongation always corresponds to local fitness optima (Figure 5D, red dots). These results further confirm the physiological cost associated with slow initiation.

The cost of initiation is most striking amongst strains with low $\mathrm{P}_{\mathrm{NC}}$ and high $\mathrm{RNA}_{\mathrm{SS}}$, whose profiles show highest skew toward low polysome fractions. Sequence variants confined to this phenotypic region are characterized by strong structures encompassing the TIR and downstream coding sequence (Figure 5C). Individually, these properties provide the requirements for slow initiation and improved transcript stability. We propose that their combined effects define a selfreinforcing catastrophic cycle whereby initially minor transcript stabilization spirals into a generalized translation decrease through a pathological transcript buildup driven by feedbacks between translation and stability (see Discussion and Figure 6F). The resulting convolution of high $\mathrm{RNA}_{\mathrm{SS}}$ with slow initiation lead to the unproductive mobilization of ribosomal labor away from other transcripts, and thus to futile fitness cost.

\section{DISCUSSION}

Nearly half the ribosomes are dedicated to producing more ribosomes in growing E. coli cells (Li et al., 2014). This poses a compelling optimization problem, whereby ribosomes must be properly allocated to achieve the fine balance between ribosome production and that of other proteins necessary to maximize cell growth (Scott et al., 2014). Failure to do so can have lasting deleterious consequences on the cell fitness, which increases the value of ribosomes far beyond their production cost. Understanding how sequence properties influence this allocation pattern is essential from both fundamental and applied perspectives.

We precisely designed systematic sequence variations in the coding sequence of a particular reporter to dissect the phenotypic consequences while controlling, as much as possible, for statistical artefacts or confounding mechanisms. While we confirm that many known sequence features such as transcript secondary structure and codon usage bias are important, we also uncover hard-to-predict feedbacks between transcript degradation, translation and cellular homeostasis and demonstrate a large amount of remaining uncertainty in mechanisms that impact translational efficiency.

The three overlapping structures we explored (Figure 1C) may have two major functional consequences: i) intrinsic protection of the transcript from degradation; and/or ii) diminution of translation through decrease of initiation and/or elongation rates. Once recruited on transcripts, ribosomes can: i) sterically protect the stretch of mRNA they are sitting on; and ii) directionally unfold structures as they proceed along the transcript, thereby opening the way for immediately following ribosomes, as well as RNases. The interplay between these mechanisms gives rise to variety of archetypal phenotypic patterns that we detail below (Figure 6).

Sequences designed with mild TIR structure and no structures otherwise may serve as a baseline reference for discussion (Figure 6B). Medium TIR structures determine largely limiting initiation rates. These are nonetheless capable of driving sizeable protein production when free ribosomes are numerous enough to support another initiation before the TIR structure opened by the preceding event can refold, a process we refer to as ribosome cooperativity. The absence of strong downstream structures and the regular ribosome flow ensure basal rates of transcript decay. The low physiological charge associated with this configuration is mostly attributable to the material cost of moderate protein biosynthesis. This cost decreases when cells are grown in less productive conditions (see $\mathrm{C}_{\mathrm{M}}$ and Figure $2 \mathrm{M}$ ). The cost of ribosome utilization is minimal because initiation is fast enough to prevent transcript accumulation (low RNA $\mathrm{SS}_{\mathrm{SS}}$ ), but slow enough to avoid ribosomal jams during subsequent elongation (medium MRD). The apparent ribosome utilization (ARU = MRD $\mathrm{x} \mathrm{RNA}_{\mathrm{SS}}$ ) is then kept at its lowest, ensuring efficient replenishment of the free ribosome pool and subsequent redistribution toward other transcripts. 
bioRxiv preprint doi: https://doi.org/10.1101/209098; this version posted October 25, 2017. The copyright holder for this preprint (which was not certified by peer review) is the author/funder, who has granted bioRxiv a license to display the preprint in perpetuity. It is made available under aCC-BY-NC-ND 4.0 International license.
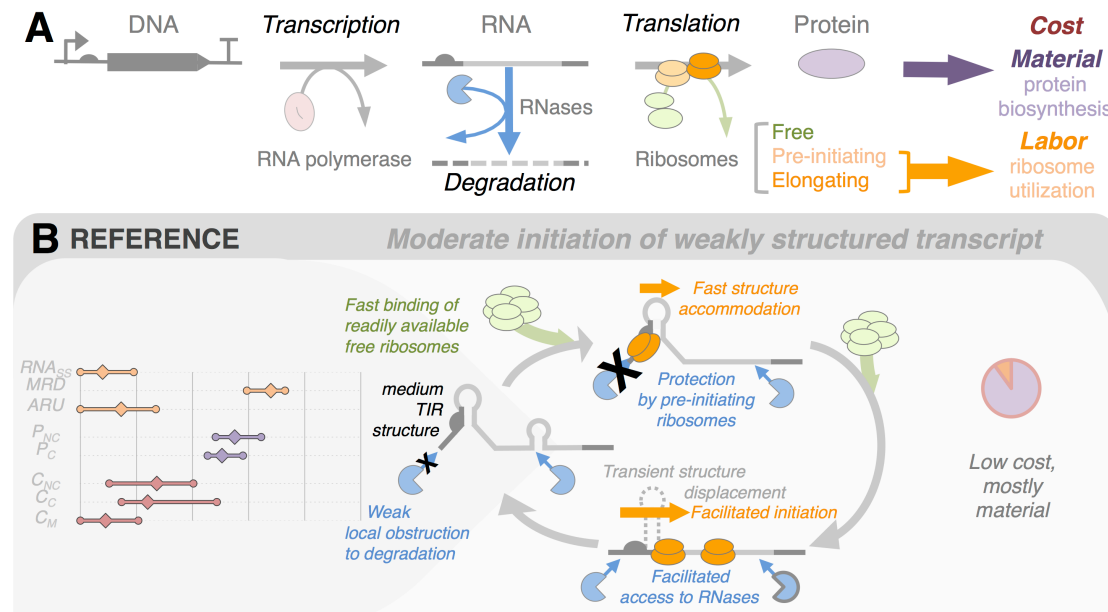

\section{UNSTRUCTURED TIR Fast initiation and codon impact on elongation}

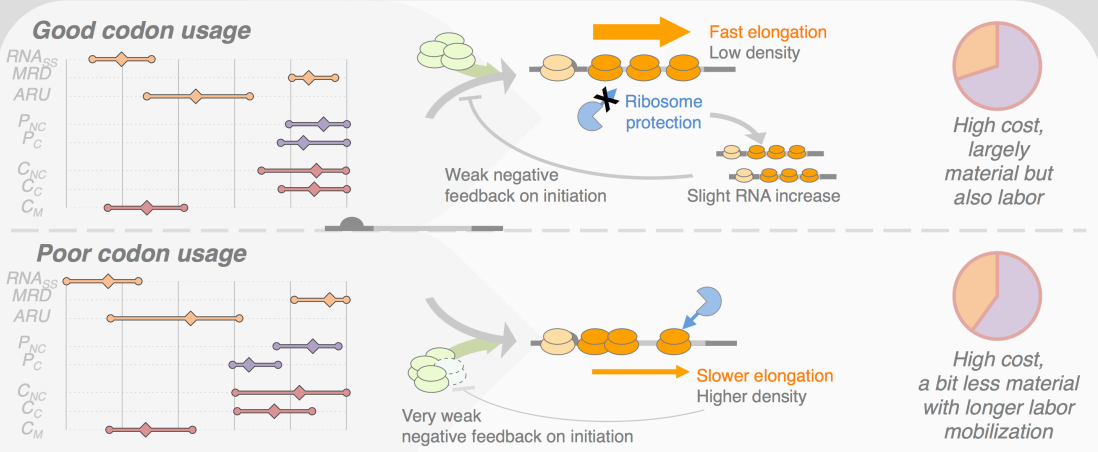

D STRUCTURED TIR ONLY

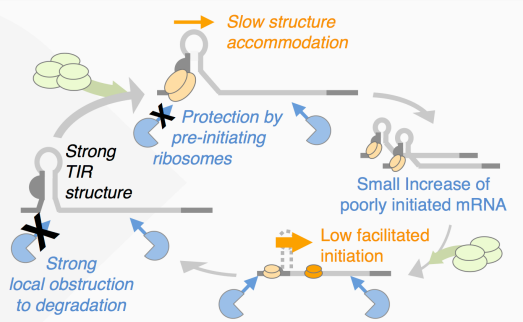

Slow initiation

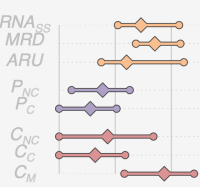

E COMPETING DISTAL STRUCTURE
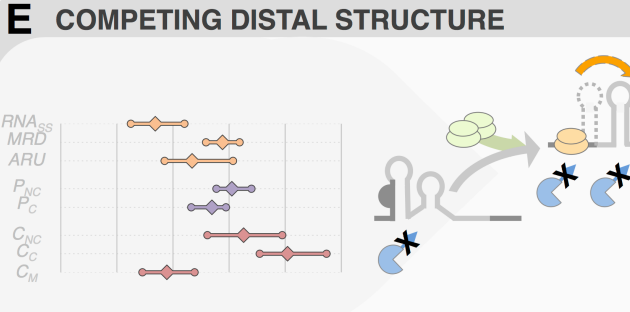

\section{F NON-COMPETING TIR \& CDS STRUCTURES}

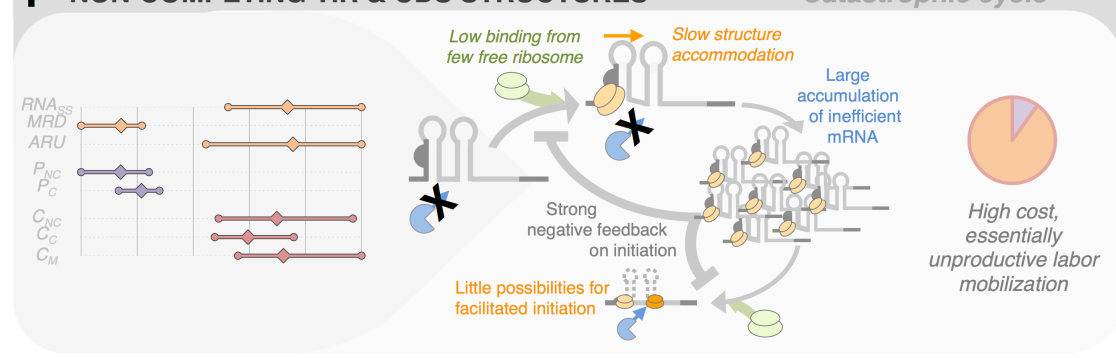

Figure 6 - Impact of archetypal sequences on controlling translation efficiency and cost (A) Key processes in the central dogma of molecular biology. This diagram introduces graphical elements used in the schematics below. (BCDEF) Combinations of sequence properties and consequent variations in translation efficiency determine diverse physiological costs. Left charts show the interquartile ranges of various measured phenotypic averages across factorial series, as shown (abbreviations as used throughout the text; the costs $\mathrm{C}_{\mathrm{NC}}, \mathrm{C}_{\mathrm{C}}$ and $\mathrm{C}_{\mathrm{M}}$ are the opposite of $\mathrm{W}_{\mathrm{NC}}$, $\mathrm{W}_{\mathrm{C}}$ and $\mathrm{W}_{\mathrm{M}}$, respectively). Schematic models in the middle provide a mechanistic framework for these data. Physiological consequences are rendered as schematic pie charts on the right, the size of which conveys the magnitude of the overall cost, while the slices differentiate material (violet) and labor (orange) contributions. Data are subset by combinations of categorical properties used for design as follow: (B) Medium STR $_{-30:+30} \cap$ Weak STR $+01: \div 60 \cap$ Weak $\mathrm{STR}_{+31:+90}$; (C) top: Weak STR $_{-30:+30} \cap$ Weak $\mathrm{STR}_{+01:+60} \cap$ High CAI; bottom: Weak STR $_{-30:+30} \cap$ Weak STR $_{+01:+60} \cap$ Weak CAI; (D) Strong $\mathrm{STR}_{-30:+30} \cap$ medium $\mathrm{STR}_{+01:+60} \cap$ weak $\mathrm{STR}_{+31:+90}$; (E) medium STR $-30:+30 \cap$ medium STR $_{+01: 60} \cap$ strong STR $+31:+90 ;$ (F) strong STR $-30 ;+30 \cap$ weak $\mathrm{STR}_{+01:+60} \cap$ strong STR $+31:+90$.

Arkin and Cambray - Massive phenotypic measurements reveal complex physiological consequences of differential transl... 9 of 13 
are limited by elongation rather than initiation. In the absence of other downstream structures, elongation rates are mostly dependent on codon usage (Figure 6C). Codon-adapted sequences support increased $\mathrm{P}_{\mathrm{NC}}$ and even more $\mathrm{P}_{\mathrm{C}}$. Although translation often favors transcript decay by disrupting otherwise stabilizing secondary structures, the situation is reversed under high initiation because translating ribosomes enter into kinetic competition with RNAses (Figure 4DE). While less codon-adapted transcripts exhibit higher MRD (Figure $5 \mathrm{~B}$ ), improved codon usage lead to higher RNA $\mathrm{PTX}_{\text {and }}$

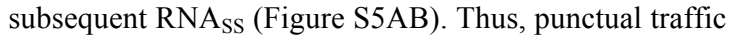
jams at slowly translated sites lead to uneven ribosomal loads and provide more endonucleolytic opportunities than a smoother ribosome flow (Figure 6C). Ribosome protection has only a marginal impact on $\mathrm{RNA}_{\mathrm{SS}}$ in our system and is most visible during the mRNA decay assay (Figure $4 \mathrm{C}$ and $3 \mathrm{E}$ ). This probably stems from our using a highly transcribed reporter, which likely limits the maximal initiation rate attainable through ribosome titration. We expect the importance of the above mechanisms to be amplified at lower transcription rates.

Under high initiation, codon adaptation is linked to a complex combination of signals, which altogether indicate smoother and more efficient elongation: increased protection, higher RNA abundance, lower ribosomal density and increased protein production. Our results supports the notion that strong codon biases in highly transcribed natural genes have been selected to minimize ribosomal retention on these transcripts (Kudla et al., 2009). Nevertheless, we only find a small positive association between CAI and growth (Figure 2J and S2IJ). Improving CAI should lead to increased fitness through lower ribosomal utilization-but would also incidentally augment ribosome protection, RNA abundance and protein production, ultimately resulting in higher material cost. The signal relating CAI to fitness might therefore be blurred by nearly compensatory transactions between these two cost components (Figure $6 C)$.

Consider now transcripts with strong TIR, but no downstream, structures (Figure 6D). Pre-initiating ribosomes that bind these molecules at unstructured upstream sites must accommodate the folded TIR to eventually initiate translation. Structure accommodation is an active process that takes place at the ribosomal platform and may occasionally require specialized chaperones, such as the ribosomal protein S1 (Duval et al., 2013). Other regulators (e.g. S15) can instead stabilize these complexes, thereby trapping ribosomes in a lasting stalled state (Marzi et al., 2007). In either case, pre-initiating ribosomes remain bound to transcript for long periods of time, during which they are effectively sequestered away from other transcripts. Here, the bound upstream sequence and the structure being unfolded are likely protected, whereas the unstructured downstream sequence is fully accessible to RNAses. This determines moderate transcript accumulation and medium ARU. Subsequent decrease in free ribosomes contributes to lower effective initiation rate through hindering timely ribosome cooperation. Given the low resulting protein production, this initiation-based ribosome sequestration must determine most of the small fitness cost measured under regular growth condition. This cost is markedly aggravated under increased ribosome limitation $\left(\mathrm{C}_{\mathrm{M}}\right.$ and Figure 2M).

The accommodation of TIR structures may be thermodynamically facilitated when associated with stronger structures overlapping downstream (Figure 6E). Subsequent improvements of initiation are, however, likely mitigated by lower elongation rates through that distal structure. Although moderately translated individually, such transcripts comprise enough structures to cumulate to intermediate level. They collectively yield sizeable protein production, though at a relatively high cost, due to high ARU. In isolation, protein production data suggested that strong distal structures could determine increased translation efficiency (companion paper). Integrative analysis instead reveals individual inefficiency and a collective performance driven by a moderate though deleterious transcript accumulation (Figure 2C and $3 \mathrm{~F}$ ).

In the worst case, distal structures are stably associated with non-overlapping TIR structures (Figure $6 \mathrm{~F}$ ). This configuration describes poorly initiated and intrinsically stable transcripts. The consequent rarity of translation minimizes structure unfolding within the coding sequence (lowest MRD) and thus ensures maximal transcript stabilization (highest $\mathrm{RNA}_{\mathrm{SS}}$ ). Titration of ribosomes by cumulating transcripts further limits the opportunities for cooperative initiation at the structured TIR (largest ARU). These interdependencies determine a catastrophic cycle of ever increasing unproductive ribosome utilization, global initiation decrease and augmented stabilization that eventually leads to extreme and futile labor costs. The absence of protein production from many such pathologically abundant transcripts highlights the tightness of the ensuing initiation lock. Subtle parameter variations departing from this situation can account for the continuum of phenotypes in our experiments. For example, slight improvement of initiation rates may lead to moderate protein production at large fitness cost if the transcripts remain stable enough to accumulate; or to lower fitness cost with little increase in protein production if, in contrast, transcripts are heavily destabilized.

The complex functional interplay of competitive structures along the transcript can be exploited for regulation, as in the mechanisms underlying riboswitches. In these cases, it is likely optimal to minimize ribosome sequestration by maintaining low transcript abundance and using an efficient RBS. Such a configuration, however, is prone to expression noise which itself may be non-optimal. When there is little TIR structure, keeping RNA high and initiation medium has recently been found to be relatively optimal (Ceroni et al., 2015). The advantage of medium initiation might arise from then lower ribosome sequestration on de facto poorly elongated heterologous transcripts despite the intended codon-optimization. Our model suggests that 
bioRxiv preprint doi: https://doi.org/10.1101/209098; this version posted October 25, 2017. The copyright holder for this preprint (which was not certified by peer review) is the author/funder, who has granted bioRxiv a license to display the preprint in perpetuity. It is made available under aCC-BY-NC-ND 4.0 International license.

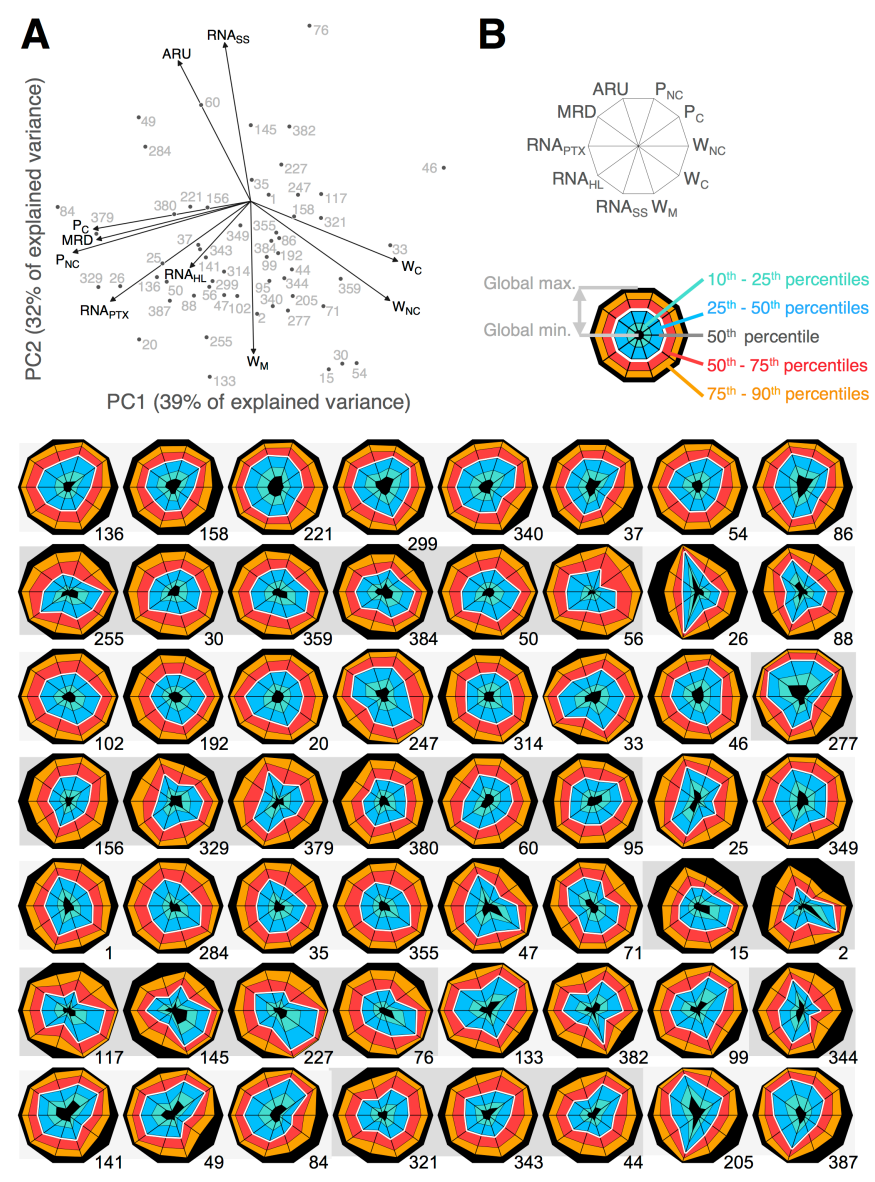

Figure 7 - Extensive phenotypic diversity between replicate factorial series

(A) Principle component analysis highlights the phenotypic spread of factorial series. The analysis is based on the correlation matrix between the serieswise means of shown phenotypic variables. (B) Visualization of the ensemble phenotypic differences between series using spider plots. Although each series explores the same property space, small initial phenotypic differences may cascade into the observed diversity. Understanding these differences represents a challenge in predictive biology.

improving the initiation-elongation balance should improve both protein production and translation capacity in that case.

Our analyses suggest that successful low-cost heterologous gene expression should rely on wellinitiated transcripts exempt of secondary structures in a TIR region spanning $\sim 50 \mathrm{nts}$ on either side of the start codon. Engineering a medium-strength structure immediately downstream of that window should impact initiation favorably by competing with unexpected TIR structure. Over-strong structure there and elsewhere in the downstream sequence can lead to transcript stabilization, slower elongation and unnecessary fitness costs. Codon usage should be optimized, but not take precedence over structure optimization. Transcription rates should be optimized, most especially in structured sequences, since high RNA abundance can uselessly sequester ribosome, potentiate the effect of secondary structures, modify the global translation regime of the cell and eventually impact fitness without necessarily improving production.

The production of ribosomes is tightly regulated. Antibiotic-mediated inhibition of translation promotes rRNA transcription in E. coli, possibly through mitigation of the stringent response driven by decreased protein biosynthesis and subsequent amino-acids accumulation (Scott et al., 2010). We expect a similar response to genetically induced perturbations that lead to sequestering of existing ribosomes. Increasing rRNAs are expected to up-regulate ribosome biogenesis (Paul et al., 2004), with potentially ambivalent consequences: although that could eventually improve the cell's translation capacity, it would momentarily mobilize dwindling ribosomes at the risk of strengthening possible deleterious feedbacks. Additional small-scale experiments on exemplary strains will be necessary to determine in which circumstances these responses are beneficial.

Normalization of protein by mRNA abundance is often used as a proxy for translation efficiency - strictly defined as the current of ribosomes over a transcript. This ratiometric approach controls for the dependence of mRNA decay and abundance on translation rate $(\mathrm{Li}$, 2015). Our results suggest that the converse relationship must also be considered. Translation efficiency is nonlinearly dependent on transcript abundance, because: i) a finite number of ribosomes must be allocated to a large excess of mRNAs; and ii) their relative availability modulates the cooperative initiation of TIR-structured transcripts. A measured protein/mRNA ratio is therefore contingent on particular conditions and not necessarily operational in other contexts. For instance, increasing the transcription of a poorly initiated construct can instigate the aforementioned catastrophe and a dramatic drop of the protein/mRNA ratio. 
The above makes clear that the complex and pleiotropic roles of RNA structures and their implications in intricate feedbacks among initiation, elongation and degradation are key to understanding physiologically efficient protein production. However, current predictions of these features and their dynamics are not accurate enough to support fully operational models (see companion paper). Other unknown sequence properties and non-linear behaviors are likely to limit our predictive power as well. As a suggestive illustration, the 56 replicate factorial series studied in this work were designed to systematically explore the exact same properties space but often show widely divergent average phenotypic responses from one another (Figure 7A). For examples: series \#26 and \#205 determine high RNA $_{\mathrm{SS}}$ and subsequent low growth, but only the former show defect in protein production; series \#56 and \#71 show weak protein production improvement under coupling, whereas \#49 instead enjoys a particularly marked increase; \#227 and \#2 produce low protein in both conditions, but while the former shows high growth in all conditions, the latter does not but nonetheless experiences large rescue under coupling (Figure 7B). The list of such idiosyncrasies is vast. Further work is needed to capture the details enabling reliable prediction

\section{REFERENCES}

Belogurov, G.A., and Artsimovitch, I. (2015). Regulation of Transcript Elongation. Annu. Rev. Microbiol. 69, 49-69.

Boël, G., Letso, R., Neely, H., Price, W.N., Wong, K.H., Su, M., Luff, J.D., Valecha, M., Everett, J.K., Acton, T.B., et al. (2016). Codon influence on protein expression in E. coli correlates with mRNA levels. Nature 529, 358-363.

Braun, F., Le Derout, J., and Régnier, P. (1998). Ribosomes inhibit an RNase E cleavage which induces the decay of the rpsO mRNA of Escherichia coli. Embo J. 17, 4790-4797.

Bulmer, M. (1991). The selection-mutation-drift theory of synonymous codon usage. Genetics 129, 897-907.

Ceroni, F., Algar, R., Stan, G.-B., and Ellis, T. (2015). Quantifying cellular capacity identifies gene expression designs with reduced burden. Nat. Methods 12, 415-418.

Deana, A., and Belasco, J.G. (2005). Lost in translation: the influence of ribosomes on bacterial mRNA decay. Genes \& Development 19, 2526-2533.

Duval, M., Korepanov, A., Fuchsbauer, O., Fechter, P., Haller, A., Fabbretti, A., Choulier, L., Micura, R., Klaholz, B.P., Romby, P., et al. (2013). Escherichia coli ribosomal protein $\mathrm{S} 1$ unfolds structured $\mathrm{mRNAs}$ onto the

Li, G.-W. (2015). How do bacteria tune translation efficiency? Curr Opin Microbiol 24, 66-71.

Li, G.-W., Burkhardt, D., Gross, C., and Weissman, J.S. (2014). Quantifying Absolute Protein Synthesis Rates from sequence alone. We have hope that this dataset will enable others to advance in that direction and inspire other endeavor in this area.

\section{AUTHOR CONTRIBUTIONS}

GC conceived the work; GC performed the experiment and processed the data; GC and APA analyzed the data; GC and APA wrote the manuscript.

\section{ACKNOWLEDGMENTS}

We thank Premal Shah, Joshua Plotkin and Luca Ciandrini for useful discussions. GC was funded by the Human Frontier Science Program (LT000873/2011-L). We acknowledge financial support by the Synthetic Biology Engineering Research Center (SynBERC). This work used the Vincent J. Coates Genomics Sequencing Laboratory at UC Berkeley (NIH S10 Instrumentation Grants S10RR029668 and S10RR027303).

ribosome for active translation initiation. PLoS Biol 11, e1001731.

Hietpas, R.T., Jensen, J.D., and Bolon, D.N.A. (2011). Experimental illumination of a fitness landscape. Proceedings of the National Academy of Sciences 108, 7896-7901.

Huch, S., and Nissan, T. (2014). Interrelations between translation and general mRNA degradation in yeast. Wiley Interdiscip Rev RNA 5, 747-763.

Hui, M.P., Foley, P.L., and Belasco, J.G. (2014). Messenger RNA degradation in bacterial cells. Annu. Rev. Genet. 48, 537-559.

Kosuri, S., Goodman, D.B., Cambray, G., Mutalik, V.K., Gao, Y., Arkin, A.P., Endy, D., and Church, G.M. (2013). Composability of regulatory sequences controlling transcription and translation in Escherichia coli. Proceedings of the National Academy of Sciences 110, 14024-14029.

Kudla, G., Murray, A.W., Tollervey, D., and Plotkin, J.B. (2009). Coding-Sequence Determinants of Gene Expression in Escherichia coli. Science 324, 255-258.

Lenz, G., Doron-Faigenboim, A., Ron, E.Z., Tuller, T., and Gophna, U. (2011). Sequence Features of E. coli mRNAs Affect Their Degradation. PLoS ONE 6, e28544.

Reveals Principles Underlying Allocation of Cellular Resources. Cell 157, 624-635.

Marzi, S., Myasnikov, A.G., Serganov, A., Ehresmann, C., Romby, P., Yusupov, M., and Klaholz, B.P. (2007). 
Structured mRNAs Regulate Translation Initiation by Binding to the Platform of the Ribosome. Cell 130, 1019-1031.

McDowall, K.J., Kaberdin, V.R., Wu, S.W., Cohen, S.N., and Lin-Chao, S. (1995). Site-specific RNase E cleavage of oligonucleotides and inhibition by stemloops. Nature 374, 287-290.

Mutalik, V.K., Guimaraes, J.C., Cambray, G., Mai, Q.A., Christoffersen, M.J., Martin, L., Yu, A., Lam, C., Rodriguez, C., Bennett, G., et al. (2013). Quantitative estimation of activity and quality for collections of functional genetic elements. Nat. Methods 10, 347-353.

Paul, B.J., Ross, W., Gaal, T., and Gourse, R.L. (2004). rRNA Transcription in Escherichia coli. Annu. Rev. Genet. 38, 749-770.

Presnyak, V., Alhusaini, N., Chen, Y.-H., Martin, S., Morris, N., Kline, N., Olson, S., Weinberg, D., Baker, K.E., Graveley, B.R., et al. (2015). Codon optimality is a major determinant of mRNA stability. Cell 160, 11111124.

Qu, X., Wen, J.-D., Lancaster, L., Noller, H.F., Bustamante, C., and Tinoco, I. (2011). The ribosome uses two active mechanisms to unwind messenger RNA during translation. Nature 475, 118-121.

Schaechter, M., MaalOe, O., and Kjeldgaard, N.O. (1958). Dependency on Medium and Temperature of
Cell Size and Chemical Composition during Balanced Growth of Salmonella typhimurium. Journal of General Microbiology 19, 592-606.

Scott, M., Gunderson, C.W., Mateescu, E.M., Zhang, Z., and Hwa, T. (2010). Interdependence of cell growth and gene expression: origins and consequences. Science 330, 1099-1102.

Scott, M., Klumpp, S., Mateescu, E.M., and Hwa, T. (2014). Emergence of robust growth laws from optimal regulation of ribosome synthesis. Mol Syst Biol 10, 747747.

Shah, P., Ding, Y., Niemczyk, M., Kudla, G., and Plotkin, J.B. (2013). Rate-Limiting Steps in Yeast Protein Translation. Cell 153, 1589-1601.

Stoebel, D.M., Dean, A.M., and Dykhuizen, D.E. (2008). The Cost of Expression of Escherichia coli lac Operon Proteins Is in the Process, Not in the Products. Genetics 178, 1653-1660.

van Opijnen, T., Bodi, K.L., and Camilli, A. (2009). Tnseq: high-throughput parallel sequencing for fitness and genetic interaction studies in microorganisms. Nat. Methods 6, 767-772.

Vogel, C., and Marcotte, E.M. (2012). Insights into the regulation of protein abundance from proteomic and transcriptomic analyses. Nat Rev Genet 13,227-232. 